\title{
Desempenho de cultivares de feijoeiro-comum em sistema orgânico de produção
}

\author{
Rodolfo Condé Fernandes ${ }^{(1)}$, José Guilherme Marinho Guerra ${ }^{(2)}$ e Adelson Paulo Araújo(3)
}

(1)Universidade Federal Rural do Rio de Janeiro (UFRRJ), Departamento de Fitotecnia, BR-465, Km 7, CEP 23851-970 Seropédica, RJ, Brasil. E-mail: agrorodolfo@gmail.com (2)Embrapa Agrobiologia, BR-465, Km 7, CEP 23891-000 Seropédica, RJ, Brasil. E-mail: guilherme.guerra@embrapa.br (3)UFRRJ, Departamento de Solos, CEP 23851-970 Seropédica, RJ, Brasil. E-mail: aparaujo@ufrrj.br

Resumo - O objetivo deste trabalho foi avaliar o crescimento e a produção de cultivares de feijoeiro-comum (Phaseolus vulgaris), de diferentes tipos comerciais de grão, em sistema orgânico de produção. Dois experimentos foram realizados em campo com 16 cultivares em delineamento experimental de blocos ao acaso, com 16 tratamentos e 4 repetições. As sementes receberam inoculação com rizóbios, tendo-se utilizado esterco bovino ao plantio e torta de mamona em cobertura. As cultivares de feijão diferiram quanto à nodulação, ao acúmulo de matéria seca e de $\mathrm{N}$ na parte aérea, à produção de grãos e aos componentes de produção, com interações significativas entre cultivares e anos quanto à produção. A produtividade média de grãos das cultivares foi de 2.035 e $1.704 \mathrm{~kg} \mathrm{ha}^{-1}$ em 2011 e 2012, respectivamente, em que se destacam BRS Pontal, BRS Campeiro, BRS Radiante, Aporé e Constanza, com produtividade acima de $1.900 \mathrm{~kg} \mathrm{ha}^{-1}$ na média dos dois anos. A produtividade foi maior nas cultivares com sementes grandes, em 2011, e maior nas de sementes pequenas em 2012. As cultivares BRS Radiante e Constanza, de grãos de tipos especiais com perspectivas de nichos de mercado com maior valor de comercialização, apresentam bom desempenho no sistema orgânico de produção.

Termos para indexação: Phaseolus vulgaris, adubação orgânica, feijões especiais, genótipo, nodulação.

\section{Performance of common bean cultivars in organic production system}

Abstract - The objective of this work was to evaluate the growth and grain yield of common bean (Phaseolus vulgaris) cultivars of different market grain types, in organic production system. Two field experiments were carried out with 16 cultivars, in a randomized complete block design with 16 treatments and four replicates. Seed were inoculated with rizobia, cattle manure was applied at sowing and castor bean press cake was applied at side dress. Bean cultivars differed for nodulation, accumulation of dry matter and $\mathrm{N}$ in the shoots, grain yield and yield components, with significant interactions between cultivars and years for grain yield. Average grain yield of cultivars was 2,035 and 1,704 kg ha' in 2011 and 2012, respectively, for which BRS Pontal, BRS Campeiro, BRS Radiante, Aporé, and Constanza outstood with more than 1,900 $\mathrm{kg} \mathrm{ha}^{-1}$ average across two years. Grain yield was higher in large-seeded cultivars, in 2011; and in small-seeded ones, in 2012. The BRS Radiante and Constanza cultivars, with grains of special types with potential for market niches with improved commercial prices, show good performance in the organic production system.

Index terms: Phaseolus vulgaris, organic fertilization, special beans, genotype, nodulation.

\section{Introdução}

Os sistemas orgânicos de produção podem contribuir com a produção sustentável de alimentos, por meio da redução da degradação do solo, do aumento da resistência de cultivos a estresses hídricos e a ataques de pragas e doenças, aumento da segurança alimentar e mitigação das mudanças climáticas (Azadi et al., 2011). A adoção de sistemas orgânicos de produção enfrenta desafios associados às produtividades mais baixas e variáveis do que em sistemas convencionais e à conversão e adaptação dos sistemas de manejo (Sacco et al., 2015). Ponti et al. (2012) compararam sistemas de produção, em diferentes regiões do mundo, e concluíram que os rendimentos da produção orgânica corresponderam a $80 \%$ dos obtidos pela agricultura convencional e que estas diferenças aumentam quanto maiores os rendimentos no sistema convencional. As eventuais reduções de produtividade em sistemas orgânicos podem ser compensadas pelo 
maior valor comercial obtido pelo produto orgânico que, todavia, depende do processo de comercialização (Post \& Schahczenski, 2012), além da redução do uso de fertilizantes e energia, que tornam estes sistemas menos dependentes de insumos externos (Maeder et al., 2002).

O feijoeiro-comum (Phaseolus vulgaris L.) é uma cultura de grande relevância para a segurança alimentar, em várias regiões do mundo, e é cultivado em uma ampla gama de ambientes e em distintos níveis tecnológicos de produção (Broughton et al., 2003). De acordo com o Censo Agropecuário de 2006 do IBGE (2009), o cultivo de feijão estava presente em 731 mil estabelecimentos rurais no Brasil, em que a agricultura familiar representava $62 \%$ da quantidade produzida. A produção nacional de feijão atingiu 3,4 milhões de toneladas, na safra 2013/2014, com produtividade média de $1.024 \mathrm{~kg} \mathrm{ha}^{-1}$; entretanto, no Distrito Federal e nos Estados de Goiás e de São Paulo a produtividade média supera $2.000 \mathrm{~kg} \mathrm{ha}^{-1}$ (Companhia Nacional de Abastecimento, 2015).

Os grãos de feijão do tipo comercial carioca representam a maior parte do mercado consumidor no Brasil, e o tipo preto é o segundo grão mais comercializado no país. Os grãos de tegumento de outras cores, como branco, creme, amarelo e vermelho, e com grãos de tamanho médio a grande e de distintos formatos, são denominados feijões de grãos especiais (Thung et al., 2009; Ribeiro et al., 2014). O cultivo desses feijões especiais constitui uma alternativa de produção, para a exploração de nichos de mercado, obtenção de um produto diferenciado e de maior valor de comercialização, além de apresentar boas perspectivas de exportação, pois há demanda por feijões de grãos especiais por parte de vários países importadores (Broughton et al., 2003; Thung et al., 2009).

A adoção de sistemas orgânicos para a produção de feijoeiro-comum demanda a identificação de cultivares mais adaptadas a este manejo, em razão das grandes variações observadas no desempenho produtivo entre genótipos, em distintos sistemas de produção (Singh et al., 2009). O emprego de cultivares selecionadas sob sistemas de cultivo convencional e pouco adaptadas ao manejo orgânico foi associado ao menor rendimento do trigo, em sistemas orgânicos, nos Estados Unidos (Murphy et al., 2007). São poucos os estudos que avaliam o desempenho do feijoeiro-comum em sistema orgânico de produção, e grande parte das informações disponíveis são provenientes de iniciativas práticas dos agricultores ou de experiências internacionais (Carvalho \& Wanderley, 2007). Assim, são necessárias avaliações do desempenho de cultivares de feijoeiro-comum, em sistemas orgânicos de produção, que contemplem genótipos com diferentes tipos de grãos e de fenologia.

O objetivo deste trabalho foi avaliar o crescimento e a produção de cultivares de feijoeiro-comum (Phaseolus vulgaris), de diferentes tipos comerciais de grãos, em sistema orgânico de produção.

\section{Material e Métodos}

Dois experimentos de campo foram realizados no Sistema Integrado de Produção Agroecológica (Sipa), Fazendinha Agroecológica do Km 47, em Seropédica, $\mathrm{RJ}$, a $22^{\circ} 45^{\prime} \mathrm{S}, 43^{\circ} 40^{\prime} \mathrm{W}$, a $26 \mathrm{~m}$ de altitude. O primeiro experimento foi realizado entre maio e agosto de 2011 , e o segundo, entre abril e agosto de 2012. A área da Fazendinha Agroecológica funciona sob o sistema de manejo orgânico desde 1993. O clima da região é do tipo Cwa, segundo Köppen, com inverno moderadamente frio e verão quente, com precipitação pluvial média anual de $1.280 \mathrm{~mm}$, e temperatura média de $22,5^{\circ} \mathrm{C}$. O solo da área é um Planossolo (Santos et al., 2006), em que a cultura da batata-doce antecedeu a implantação do primeiro experimento. Os dados meteorológicos, durante a condução dos experimentos, foram obtidos pela Estação Ecologia Agrícola, em Seropédica, RJ, e registraram valores médios de temperatura de 20,2 e $21,1^{\circ} \mathrm{C}$ e de umidade relativa do ar de 81,0 e $82,3 \%$, em 2011 e 2012, respectivamente.

$\mathrm{O}$ experimento foi realizado em um delineamento de blocos ao acaso, com 16 tratamentos e 4 repetições, com parcelas de 5 linhas de $4 \mathrm{~m}$ cada uma, espaçadas em $0,5 \mathrm{~m}$ entre si. Foram avaliadas 16 cultivares comerciais de feijoeiro-comum (Tabela 1), algumas estudadas em cultivo convencional em Argissolo, em Seropédica, RJ (Araújo \& Teixeira, 2008, 2012).

A análise de solo da área experimental, na camada de 0-20 cm, efetuada de acordo com Silva et al. (2009), apresentou os atributos químicos a seguir descritos. Em 2011: $\mathrm{pH}$ em água de 5,3; $\mathrm{Al}, 0,1 \mathrm{cmol}_{\mathrm{c}} \mathrm{dm}^{-3} ; \mathrm{Ca}$, 2,3 $\mathrm{cmol}_{\mathrm{c}} \mathrm{dm}^{-3} ; \mathrm{Mg}, 1,1 \mathrm{cmol}_{\mathrm{c}} \mathrm{dm}^{-3} ; \mathrm{P}, 38 \mathrm{mg} \mathrm{dm}^{-3}$; e $\mathrm{K}, 60 \mathrm{mg} \mathrm{dm}{ }^{-3}$. Em 2012: $\mathrm{pH}$ em água 5,2; $\mathrm{Al}$, 
0,1 $\mathrm{cmol}_{\mathrm{c}} \mathrm{dm}^{-3} ; \mathrm{Ca}, 1,8 \mathrm{cmol}_{\mathrm{c}} \mathrm{dm}^{-3} ; \mathrm{Mg}, 1,2 \mathrm{cmol}_{\mathrm{c}} \mathrm{dm}^{-3}$; P, $36 \mathrm{mg} \mathrm{dm}^{-3}$; e K, $56 \mathrm{mg} \mathrm{dm}^{-3}$.

O preparo do solo foi efetuado por meio de aração, e não foi feita a calagem. Antes da implantação dos experimentos, uma nova aração, gradagem e sulcamento foram realizados. Nas adubações de plantio, aplicaramse $2 \mathrm{~L}$ de esterco bovino curtido (com 14,5 $\mathrm{g} \mathrm{kg}^{-1}$ de $\mathrm{N}$ total, oriundo de vacas de leite manejadas dentro da própria Fazendinha) por metro linear de sulco, ou cerca de $6 \mathrm{Mg} \mathrm{ha}^{-1}$, com uma estimativa de $87 \mathrm{~kg} \mathrm{ha}^{-1}$ de N. Aos 30 dias após o plantio, aplicaram-se, em cobertura, $55 \mathrm{~g}$ de torta de mamona (com $46 \mathrm{~g} \mathrm{~kg}^{-1} \mathrm{de}$ $\mathrm{N}$ total), adquirida em sacas no mercado, por metro linear, ou cerca de $1 \mathrm{Mg} \mathrm{ha}^{-1}$, com uma estimativa de $46 \mathrm{~kg} \mathrm{ha}^{-1}$ de N aplicado. Semearam-se 12 sementes por metro linear, com adição de inoculante comercial para feijoeiro-comum, fornecido pela Embrapa Agrobiologia, que continha as estirpes de Rhizobium tropici BR322 (CIAT 899) e BR520 (PRF81), em turfa como meio de inoculação.

Para o controle de plantas daninhas, aos 15 dias após o plantio, realizou-se uma capina com enxada, entre as linhas, e com arranque manual, dentro das linhas de plantio. Durante a capina no ano de 2011, identificaramse sintomas de rizoctoniose, cujo controle foi efetuado com pulverização do produto Trichorbio concentrado (Agribio Defensivos Alternativos, Seropédica, RJ,
Brasil). A presença de Diabrotica speciosa (vaquinha) foi controlada com duas pulverizações com óleo de nim a $0,5 \%$, nos dois anos. A área experimental foi irrigada por aspersão até duas vezes por semana, de acordo com a demanda da cultura.

No experimento de 2011, efetuaram-se duas amostragens de massa de matéria seca de raízes e da parte aérea e nodulação, a primeira, quando da plena floração de cada cultivar (Tabela 1), e a segunda, 14 dias depois, no início do enchimento de vagens. As plantas presentes em $0,5 \mathrm{~m}$ linear da segunda linha, de cada parcela, foram colhidas com auxílio de uma pá reta e separadas em raízes e parte aérea. As raízes foram lavadas e os nódulos separados. A parte aérea, raízes e nódulos foram secos em estufa a $70^{\circ} \mathrm{C}$ e pesados.

Durante a maturação dos grãos de cada cultivar, retiraram-se as plantas de uma área de $1 \mathrm{~m}^{2}$, nas duas linhas centrais de cada parcela. O número de plantas e de vagens foram contados; as vagens foram trilhadas manualmente, e os grãos foram pesados. $\mathrm{Na}$ área útil restante de $2 \mathrm{~m}^{2}$, a massa dos grãos foi mensurada $\mathrm{e}$, com sua soma à massa de grãos da área de $1 \mathrm{~m}^{2}$, obteve-se a produção de grãos, corrigida para $13 \%$ de umidade. Os grãos foram passados por tamiz, tendo-se estimado as perdas por grãos quebrados. Os materiais vegetais obtidos das amostragens de massa de matéria seca e da colheita de grãos, em 2011, foram moídos,

Tabela 1. Características das cultivares de feijoeiro-comum, avaliadas em dois experimentos de campo (2011 e 2012) em sistema orgânico de produção, em Seropédica, RJ.

\begin{tabular}{|c|c|c|c|c|c|c|c|}
\hline \multirow[t]{2}{*}{ Cultivar } & \multirow[t]{2}{*}{ Tipo de grão } & \multirow[t]{2}{*}{ Arquitetura } & \multirow{2}{*}{$\begin{array}{c}\text { Massa de } 100 \\
\text { sementes }(\mathrm{g})\end{array}$} & \multicolumn{2}{|c|}{ Floração (dias após a emergência) } & \multicolumn{2}{|c|}{ Ciclo (dias após a emergência) } \\
\hline & & & & 2011 & 2012 & 2011 & 2012 \\
\hline BRS Radiante & Rajado & Semiereto & 42,4 & 30 & 29 & 80 & 77 \\
\hline Bolinha & Amarelo & Ereto & 38,9 & 31 & 30 & 83 & 76 \\
\hline Jalo Precoce & Jalo & Semiereto & 42,0 & 33 & 32 & 83 & 74 \\
\hline Kaboon & Branco & Ereto & 48,5 & 33 & 30 & 82 & 77 \\
\hline Manteigão & Manteiga & Semiereto & 45,6 & 33 & 31 & 84 & 81 \\
\hline Constanza & Vermelho & Ereto & 51,7 & 35 & 31 & 89 & 80 \\
\hline Ouro Negro & Preto & Prostrado & 25,3 & 35 & 33 & 89 & 77 \\
\hline BRS Marfim & Mulatinho & Semiereto & 28,4 & 37 & 37 & 89 & 79 \\
\hline BRS Campeiro & Preto & Ereto & 27,1 & 37 & 37 & 85 & 73 \\
\hline BRS Valente & Preto & Ereto & 23,2 & 39 & 38 & 91 & 78 \\
\hline BRS Supremo & Preto & Ereto & 23,6 & 39 & 28 & 83 & 78 \\
\hline BRS Pitanga & Roxo & Semiereto & 21,8 & 39 & 39 & 83 & 73 \\
\hline Aporé & Carioca & Semiereto & 28,4 & 39 & 38 & 88 & 78 \\
\hline BRS Pontal & Carioca & Prostrado & 27,2 & 39 & 38 & 87 & 78 \\
\hline BRS Estilo & Carioca & Ereto & 28,6 & 41 & 40 & 85 & 76 \\
\hline BRS Vereda & Rosinha & Prostrado & 25,3 & 41 & 40 & 92 & 76 \\
\hline
\end{tabular}


e o teor de $\mathrm{N}$ foi determinado pelo método semimicro Kjeldahl (Silva et al., 2009). O conteúdo de $\mathrm{N}$ de cada porção vegetal foi obtido pelo produto entre o teor de $\mathrm{N}$ e a massa de matéria seca.

A análise de variância foi realizada para cada experimento, tendo-se considerado um único fator, a cultivar. A soma dos quadrados foi decomposta para fornecer um contraste entre as cultivares de sementes grandes (massa de 100 grãos acima de $40 \mathrm{~g}$ ) e de sementes pequenas. Calculou-se a correlação simples entre os caracteres, com repetições, com significância estimada pelo teste t. Procedeu-se à análise de variância conjunta dos dois experimentos como um fatorial duplo, tendo-se avaliado o efeito de ano, cultivar e da interação. As médias foram comparadas pelo teste de Duncan, a $5 \%$ de probabilidade.

\section{Resultados e Discussão}

As cultivares de feijoeiro diferiram entre si quanto à nodulação e à acumulação de massa de matéria seca e de $\mathrm{N}$ da parte aérea, nos estádios de floração e início de enchimento de vagens, no experimento em 2011 (Figura 1). Na floração, as maiores massas de nódulos foram observadas nas cultivares BRS Supremo e BRS Vereda e, aos 14 dias após a floração, nas cultivares Ouro Negro e BRS Estilo. A cultivar BRS Vereda apresentou um grande decréscimo de nodulação após a floração, enquanto a cultivar Ouro Negro apresentou aumento de nodulação. A nodulação do feijoeiro foi intensa, particularmente no estádio de floração, com valores superiores aos registrados por Araújo et al. (2000), em sistema de cultivo tradicional, com inoculação de rizóbio em Seropédica, RJ.

$\mathrm{Na}$ floração, as maiores massas de matéria seca da parte aérea foram observadas nas cultivares Aporé e BRS Campeiro e, 14 dias depois, na cultivar BRS Marfim. A produção de massa de matéria seca de parte aérea foi superior à registrada por Araújo \& Teixeira (2008), nestes mesmos estádios fenológicos, em sistema de cultivo convencional, em Seropédica, RJ, com algumas cultivares idênticas às avaliadas no presente trabalho, o que mostra um adequado crescimento das cultivares no sistema orgânico de produção. Os maiores conteúdos de $\mathrm{N}$ da parte aérea foram observados na cultivar Aporé, na floração, e nas cultivares Constanza e na BRS Supremo, no início de enchimento das vagens (Figura 1).
Houve uma grande diferença de crescimento vegetal entre as duas épocas de amostragem (Figura 1), com aumento da massa de matéria seca de parte aérea de 139 para $272 \mathrm{~g} \mathrm{~m}^{-2}$, e da massa de matéria seca da raiz de $16 \mathrm{~g} \mathrm{~m}^{-2}$ para $22 \mathrm{~g} \mathrm{~m}^{-2}$, nos estádios de floração e início de enchimento de vagens, respectivamente, na média de todas as cultivares. No mesmo período, ocorreu um grande incremento da acumulação de $\mathrm{N}$ na parte aérea, de $5,47 \mathrm{~g} \mathrm{~m}^{-2}$ na floração para $9,55 \mathrm{~g} \mathrm{~m}^{-2}$ 14 dias depois. No início de enchimento de vagens, é intensa a acumulação de massa de matéria seca e de nutrientes do feijoeiro, período crítico para o adequado crescimento do cultivo e obtenção de elevada produção de grãos (Araújo \& Teixeira, 2008).

Houve redução da massa de nódulos, entre os estádios de floração e início de enchimento de vagens, de 73 para $54 \mathrm{mg}$ por planta, respectivamente (Figura 1), o que denota um processo de senescência de nódulos nos estádios reprodutivos, que está associado à menor aquisição de $\mathrm{N}$ simbiótico pelo feijoeiro (Piha \& Munns, 1987). Todavia, as quantidades de $\mathrm{N}$ oriundos da simbiose podem representar um aporte expressivo de $\mathrm{N}$ para o feijoeiro (Hardarson et al., 1993), que pode assumir ainda maior relevância em sistemas orgânicos de produção, em que a menor disponibilidade de nutrientes oriunda da mineralização dos fertilizantes orgânicos pode reduzir o rendimento dos cultivos em algumas situações (Sacco et al., 2015). Graham et al. (2003) relacionaram alguns caracteres com potencial para a seleção de genótipos de feijoeiro, com maior contribuição do $\mathrm{N}$ oriundo da simbiose, tais como massa de nódulos, duração do período de fixação de N, retardamento da senescência nodular, alta acumulação de massa de matéria e de $\mathrm{N}$ da parte aérea. Neste sentido, pode-se destacar a elevada nodulação do feijoeiro 'Ouro Negro', no início de enchimento de vagens, e a elevada nodulação durante a floração e a acumulação de $\mathrm{N}$ no enchimento de vagens do feijoeiro 'BRS Supremo'.

Com a análise de variância conjunta dos dois experimentos, evidenciaram-se efeitos significativos dos anos e das cultivares, na produção de grãos e nos componentes de produção, cominterações significativas entre anos e cultivares quanto à produção de grãos, ao número de grãos por vagem e à massa de 100 grãos (Tabela 2). Interações significativas entre genótipos e ambientes de cultivo quanto à produtividade de feijoeiro também foram observadas por Carvalho \& 

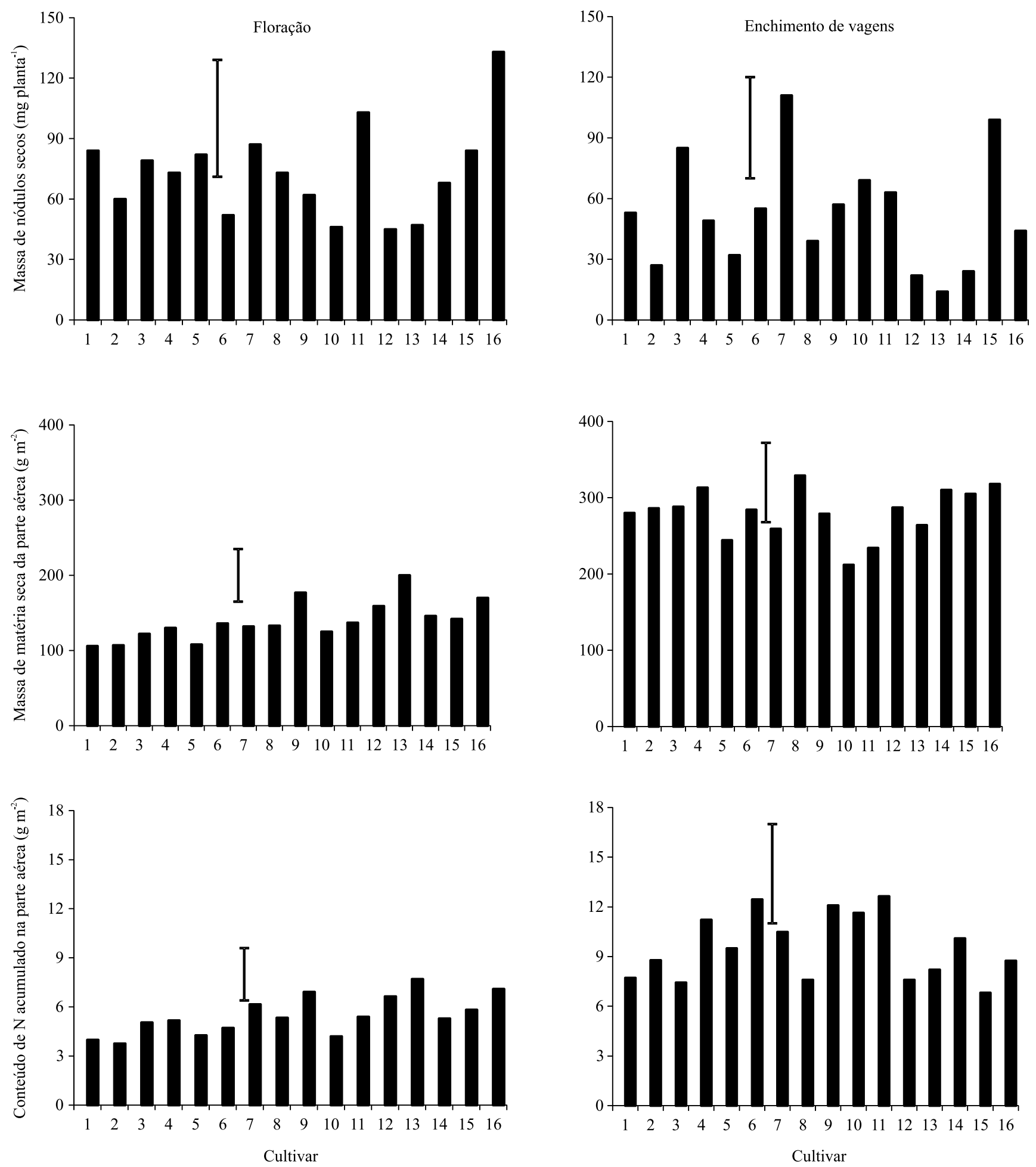

Figura 1. Massa de nódulos secos, massa de matéria seca de parte aérea e conteúdo de $\mathrm{N}$ acumulado na parte aérea de 16 cultivares de feijoeiro-comum, nos estádios de floração (coluna esquerda) e início de enchimento de vagens (14 dias após a floração, coluna direita), em sistema orgânico de produção em Seropédica, RJ, em 2011. Barras verticais representam a diferença mínima significativa entre cultivares, pelo teste de Duncan, a 5\% de probabilidade. Cultivares: 1, BRS Radiante; 2 , Bolinha; 3, Jalo Precoce; 4, Kaboon; 5, Manteigão; 6, Constanza; 7, Ouro Negro; 8, BRS Marfim; 9, BRS Campeiro; 10, BRS Valente; 11, BRS Supremo; 12, BRS Pitanga; 13, Aporé; 14, BRS Pontal; 15, BRS Estilo; 16, BRS Vereda. 
Wanderley (2007), em sistema orgânico, no Distrito Federal, e por Singh et al. (2009), em diferentes sistemas de produção, inclusive orgânicos, nos Estados Unidos. Estas interações entre genótipos e ambiente de cultivo requerem a escolha criteriosa dos locais para avaliação do germoplasma de feijoeiro (Singh et al., 2009).

A produtividade média de grãos foi de 2.035 e $1.704 \mathrm{~kg} \mathrm{ha}^{-1}$, nos anos de 2011 e 2012, respectivamente

Tabela 2. Valores de quadrado médio da análise de variância dos dados de produção de grãos e componentes de produção de 16 cultivares de feijoeiro-comum, avaliadas em sistema orgânico de produção em Seropédica, RJ, nos anos de 2011 e 2012 .

\begin{tabular}{lccccc}
\hline $\begin{array}{l}\text { Fonte de } \\
\text { variação }\end{array}$ & $\begin{array}{c}\text { GL } \\
\text { Produção de } \\
\text { grãos }\end{array}$ & $\begin{array}{c}\text { Número de } \\
\text { vagens por } \\
\text { planta }\end{array}$ & $\begin{array}{c}\text { Número de } \\
\text { grãos por } \\
\text { vagem }\end{array}$ & $\begin{array}{c}\text { Massa de } \\
100 \text { grãos }\end{array}$ \\
\hline Ano & 1 & $3939625^{*}$ & $7938,0^{* *}$ & $212,7 *$ & $4118^{*}$ \\
Erro A & 6 & 386644 & 298,2 & 33,1 & 545 \\
Cultivar & 15 & $296226^{* *}$ & $930,8^{* * *}$ & $546,2 * * *$ & $125970^{* * *}$ \\
Ano x cultivar & 15 & $212872^{*}$ & 96,6 & $48,8 * *$ & $2455^{* * *}$ \\
Erro B & 90 & 103964 & 184,0 & 20,8 & 439 \\
\hline CV $(\%)$ & & 18,51 & 18,19 & 11,58 & 6,15 \\
\hline
\end{tabular}

$*$, ** e ***Significativo a 5,1 e $0,1 \%$ de probabilidade, pelo teste $\mathrm{F}$.
(Tabela 3), superiores à média nacional e do Estado do Rio de Janeiro, na safra 2012/2013, de 913 e $967 \mathrm{~kg} \mathrm{ha}^{-1}$, respectivamente (Companhia Nacional de Abastecimento, 2015). Em geral, a qualidade dos grãos foi excelente, com perda média de $2,9 \%$ de grãos quebrados, com maior perda nas cultivares de grãos maiores, particularmente Manteigão e Constanza, respectivamente de 7,3 e 12,0\%. Em 2011, as cultivares Aporé, BRS Pontal, BRS Campeiro, BRS Vereda, BRS Radiante e BRS Marfim apresentaram produtividade acima de $2.000 \mathrm{~kg} \mathrm{ha}^{-1}$. Em 2012, as cultivares mais produtivas foram Constanza, BRS Valente, BRS Radiante e Kaboon, com produtividade entre 1.900 e $2.000 \mathrm{~kg} \mathrm{ha}{ }^{-1}$. $\mathrm{Na}$ média dos dois anos, as cultivares BRS Pontal, BRS Campeiro, BRS Radiante, Aporé e Constanza apresentaram produtividade superior a $1.900 \mathrm{~kg} \mathrm{ha}^{-1}$. As produtividades médias obtidas no presente trabalho são similares às registradas em sistemas de produção orgânica, no Distrito Federal, de $1.928 \mathrm{~kg} \mathrm{ha}^{-1}$, em quatro cultivos (Carvalho \& Wanderley, 2007). Sistemas orgânicos de produção de alto ingresso de insumos propiciaram rendimentos de feijoeiro similares aos obtidos em sistemas convencionais nos Estados Unidos, mas sistemas orgânicos com baixo

Tabela 3. Produção de grãos, número de vagens por planta, número de grãos por vagem e massa de 100 grãos de 16 cultivares de feijoeiro-comum, avaliadas em sistema orgânico de produção em Seropédica, RJ, nos anos de 2011 e 2012.

\begin{tabular}{|c|c|c|c|c|c|c|c|c|}
\hline \multirow[t]{2}{*}{ Cultivar } & \multicolumn{2}{|c|}{ Produção de grãos $\left(\mathrm{g} \mathrm{m}^{-2}\right)$} & \multicolumn{2}{|c|}{ Número de vagens por planta } & \multicolumn{2}{|c|}{ Número de grãos por vagem } & \multicolumn{2}{|c|}{ Massa de 100 grãos (g) } \\
\hline & 2011 & 2012 & 2011 & 2012 & 2011 & 2012 & 2011 & 2012 \\
\hline BRS Radiante & 220,4 & 192,3 & 7,8 & 6,5 & 3,2 & 3,0 & 47,2 & 47,8 \\
\hline Bolinha & 189,7 & 173,3 & 7,4 & 6,8 & 3,5 & 3,2 & 39,5 & 39,6 \\
\hline Jalo Precoce & 173,1 & 161,5 & 7,1 & 5,3 & 2,8 & 3,3 & 43,4 & 43,1 \\
\hline Kaboon & 184,9 & 191,0 & 7,4 & 6,3 & 3,0 & 2,8 & 51,3 & 50,9 \\
\hline Manteigão & 190,8 & 182,7 & 5,5 & 5,3 & 3,9 & 3,4 & 48,1 & 50,1 \\
\hline Constanza & 193,9 & 201,3 & 6,3 & 5,2 & 2,5 & 2,4 & 55,3 & $68,2 *$ \\
\hline Ouro Negro & 183,6 & 178,6 & 9,4 & 8,1 & 3,9 & 4,0 & 26,3 & 27,3 \\
\hline BRS Marfim & 207,7 & $156,3^{*}$ & 9,2 & $7,2 *$ & 4,2 & 3,8 & 23,8 & $28,0 *$ \\
\hline BRS Campeiro & 235,3 & 187,7 & 8,9 & $7,0 *$ & 5,4 & $4,0^{*}$ & 26,5 & 28,1 \\
\hline BRS Valente & 173,4 & 192,7 & 9,1 & 8,0 & 4,2 & 4,3 & 23,7 & 24,9 \\
\hline BRS Supremo & 176,5 & 143,9 & 8,1 & 6,5 & 5,1 & 4,8 & 23,6 & 23,1 \\
\hline BRS Pitanga & 186,4 & 152,9 & 9,8 & $7,4^{*}$ & 4,0 & 3,7 & 21,5 & 22,3 \\
\hline Aporé & 270,6 & $140,8 *$ & 10,6 & $7,7 *$ & 5,3 & $4,3 *$ & 27,7 & 25,9 \\
\hline BRS Pontal & 259,2 & $164,5^{*}$ & 8,5 & 6,7 & 5,3 & 5,0 & 25,7 & 25,6 \\
\hline BRS Estilo & 188,8 & 166,3 & 8,6 & 6,9 & 3,9 & 4,3 & 27,2 & 26,4 \\
\hline BRS Vereda & 221,6 & $140,2^{*}$ & 8,5 & $6,2^{*}$ & 4,9 & 5,0 & 26,0 & $23,6^{*}$ \\
\hline DMS & 7,1 & 7,1 & 2,3 & 2,3 & 0,8 & 0,8 & 3,6 & 3,6 \\
\hline Média & 203,5 & $170,4 *$ & 8,2 & $6,7^{*}$ & 4,1 & $3,8^{*}$ & 33,5 & $34,7^{*}$ \\
\hline
\end{tabular}

*Significativo, entre anos, pelo teste de Duncan, a 5\% de probabilidade. DMS, diferença mínima significativa entre cultivares, pelo teste de Duncan, a 5\% de probabilidade. 
ingresso de insumos apresentaram baixos rendimentos (Singh et al., 2009), o que denota que os sistemas orgânicos requerem um ajuste adequado do sistema de manejo.

Houve redução da produtividade média de grãos entre os anos de 2011 e 2012, que foi acompanhada de redução do número de vagens por planta e do número de grãos por vagem (Tabela 3). No entanto, a massa de 100 grãos foi maior em 2012. Esta redução de produtividade em 2012 foi mais acentuada nas cultivares Aporé, BRS Vereda, BRS Pontal e BRS Marfim, todas com sementes pequenas, enquanto Kaboon, Constanza e BRS Valente mantiveram produção similar nos dois anos. A cultivar Aporé - a mais produtiva em 2011, mas com intensa redução da produção em 2012 -, apresentou redução do número de vagens por planta e do número de grãos por vagem. A cultivar BRS Marfim apresentou uma intensa plasticidade, com redução da produção e do número de vagens por planta em 2012, mas com aumento da massa de 100 grãos. A cultivar Constanza apresentou aumento da massa de 100 grãos entre 2011 e 2012, o que funcionou como efeito compensatório para a produtividade.

Essa redução de produtividade em 2012 pode ser atribuída principalmente a uma maior precipitação nesse ano, que contribuiu para o excesso de água no Planossolo local, de drenagem restrita, o que pode ter limitado o desenvolvimento da cultura, em razão da grande sensibilidade do feijoeiro ao excesso de água (Moreira et al., 1996). Araújo \& Teixeira (2008) constataram grandes diferenças de produtividade entre dois anos consecutivos de plantio de cultivares de feijoeiro em Seropédica, RJ, que foi associado a um maior crescimento e acumulação de $\mathrm{N}$ e $\mathrm{P}$, no início dos estádios reprodutivos, no ano de maior produtividade. As cultivares avaliadas apresentaram redução da duração do ciclo em 2012, em comparação a 2011 (Tabela 1), que pode ter influenciado a redução da produção em 2012. Ribeiro et al. (2014) constataram variações na duração do ciclo, entre ambientes de cultivo, em linhagens de feijoeiro de grãos especiais no Rio Grande do Sul, com maior produtividade obtida com ciclos mais longos, quando do uso de irrigação.

Nos dois anos, a produção de grãos correlacionouse positivamente ao número de vagens por planta (Tabela 4). Em 2011, a produção correlacionou-se ao número de grãos por vagem e, em 2012 à massa de 100 grãos. Nos dois anos, houve correlação positiva entre número de vagens por planta e número de grãos por vagem, e uma forte correlação negativa entre número de vagens por planta e massa de 100 grãos. Apesar das dificuldades para comparar estimativas das correlações entre caracteres, o número de vagens por planta é frequentemente o componente com maior participação na produção de grãos do feijoeiro (Ramalho et al., 1993), o que foi confirmado pela correlação positiva entre produtividade e número de vagens por planta, nos dois experimentos.

Em 2011, nas cultivares com sementes grandes, a produtividade foi inferior (BRS Radiante, Bolinha, Jalo Precoce, Kaboon, Manteigão e Constanza) à dos materiais com sementes pequenas (em que se inserem as cultivares com grãos dos tipos preto e carioca), com médias de 1.921 e $2.035 \mathrm{~kg} \mathrm{ha}^{-1}$, respectivamente (teste $\mathrm{F}$ do contraste significativo, a $5 \%$ de probabilidade). Carvalho \& Wanderley (2007) observaram que as cultivares com grãos do tipo preto e carioca apresentaram rendimentos superiores aos dos materiais com outros tipos comerciais de grãos, em sistema orgânico, no Distrito Federal. Em 2012, os materiais de sementes grandes apresentaram produtividade superior à dos materiais de sementes pequenas, respectivamente, 1.837 e $1.704 \mathrm{~kg} \mathrm{ha}^{-1}$ (teste $\mathrm{F}$ do contraste significativo, a $1 \%$ de probabilidade), o que é consubstanciado pela correlação positiva entre produção e massa de 100 grãos em 2012 (Tabela 4). Araújo \& Teixeira (2003) também observaram maior produtividade das cultivares de sementes pequenas, em um ano de maior rendimento; e maior produtividade das cultivares de sementes grandes, em um ano de menor rendimento, em cultivo convencional, em Seropédica, RJ. Isso é uma indicação de bom potencial produtivo das cultivares com grãos

Tabela 4. Coeficientes de correlação simples entre a produção de grãos e os componentes de produção de 16 cultivares de feijoeiro-comum, avaliadas em sistema orgânico de produção em Seropédica, RJ, nos anos de 2011 e 2012 .

\begin{tabular}{lcc}
\hline Correlação & 2011 & 2012 \\
\hline Produção x número de plantas & $-0,121$ & 0,240 \\
Produção x número de vagens por planta & $0,364 * *$ & $0,308^{*}$ \\
Produção x número de grãos por vagem & $0,358^{* *}$ & $-0,161$ \\
Produção x massa de 100 grãos & 0,042 & $0,348^{* *}$ \\
№ de vagens por planta x no de grãos por vagem & $0,274 *$ & $0,317 *$ \\
№ de grãos por vagem x massa de 100 grãos & $-0,651 * * *-0,798^{* * *}$ \\
\hline \multirow{2}{*}{,$* *$ e ***Significativo a 5, 1 e 0,1\% de probabilidade, respectivamente, } \\
pelo teste t de Student.
\end{tabular}

Pesq. agropec. bras., Brasília, v.50, n.9, p.797-806, set. 2015 DOI: 10.1590/S0100-204X2015000900008 
especiais, em cultivos de inverno sob irrigação, na Região Sudeste do Brasil. Os genótipos de sementes grandes são predominantemente de origem Andina, e muitas cultivares deste grupo apresentam porte ereto e menor duração do ciclo (Singh et al., 1991; Ribeiro et al., 2014; Tabela 1), o que pode facilitar o manejo em sistemas orgânicos de produção.

$\mathrm{O}$ teor de $\mathrm{N}$ dos grãos, que está associado à quantidade de proteína e à qualidade nutricional dos grãos (Broughton et al., 2003), variou entre 31,3 e $40,3 \mathrm{mg} \mathrm{g}^{-1}$ entre as cultivares (Figura 2), com valor médio de $37,4 \mathrm{mg} \mathrm{g}^{-1}$. As cultivares Jalo Precoce e BRS Vereda apresentaram os maiores teores de $\mathrm{N}$ no grão, e a Aporé apresentou teor de $\mathrm{N}$ inferior. $\mathrm{O}$ conteúdo de $\mathrm{N}$ nos grãos variou entre 5,70 e $8,18 \mathrm{~g} \mathrm{~m}^{-2}$, com valores maiores nas cultivares BRS Pontal, BRS Vereda, BRS Campeiro e Aporé. Westermann et al. (2011) observaram média de 6,4 e $15,0 \mathrm{~g} \mathrm{~m}^{-2}$ para conteúdo de $\mathrm{N}$ nos grãos de 16 genótipos de feijoeiro-comum, em sistema orgânico de baixo e alto ingresso de insumos, respectivamente, enquanto Araújo \& Teixeira (2012) observaram média de $10,3 \mathrm{~g} \mathrm{~m}^{-2}$ para 64 genótipos de feijoeiro em cultivo convencional, superior à média de $6,5 \mathrm{~g} \mathrm{~m}^{-2}$ observada no presente estudo.

As cultivares de feijoeiro-comum avaliadas diferiram quanto à produção de grãos e aos componentes de produção nos dois experimentos, o que indica variabilidade no desempenho de cultivares, em sistema orgânico de produção, que também é afetada pelas condições ambientais de cultivo (Singh et al., 2009). As cultivares com grãos de tipo comercial carioca e preto, como BRS Pontal, BRS Campeiro e Aporé, apresentaram produtividade acima de $2.000 \mathrm{~kg} \mathrm{ha}^{-1}$, na média dos dois anos, o que denota o potencial de produção orgânica dos feijões com maior demanda de mercado no Brasil. Todavia, as cultivares de grãos especiais, com perspectivas de ocupação de nichos de mercado com maior valor de comercialização, mostraram bom desempenho, em particular BRS Radiante, Constanza, Kaboon e Manteigão, com produtividade superior a $1.800 \mathrm{~kg} \mathrm{ha}^{-1}$, na média dos dois anos.

No sistema de produção orgânico estudado, foram utilizadas a inoculação das sementes com rizóbio e a aplicação de esterco bovino e de torta de mamona, além da pulverização de Trichorbio e óleo de nim, o que indica um custo de produção relativamente reduzido, em caso da disponibilidade destes insumos biológicos para o produtor. Com o rendimento adequado de grãos obtidos, com grãos de boa qualidade comercial e a perspectiva de obtenção de maior preço de mercado, em particular dos feijões com grãos especiais, vislumbra-se uma boa rentabilidade da produção orgânica de feijão.
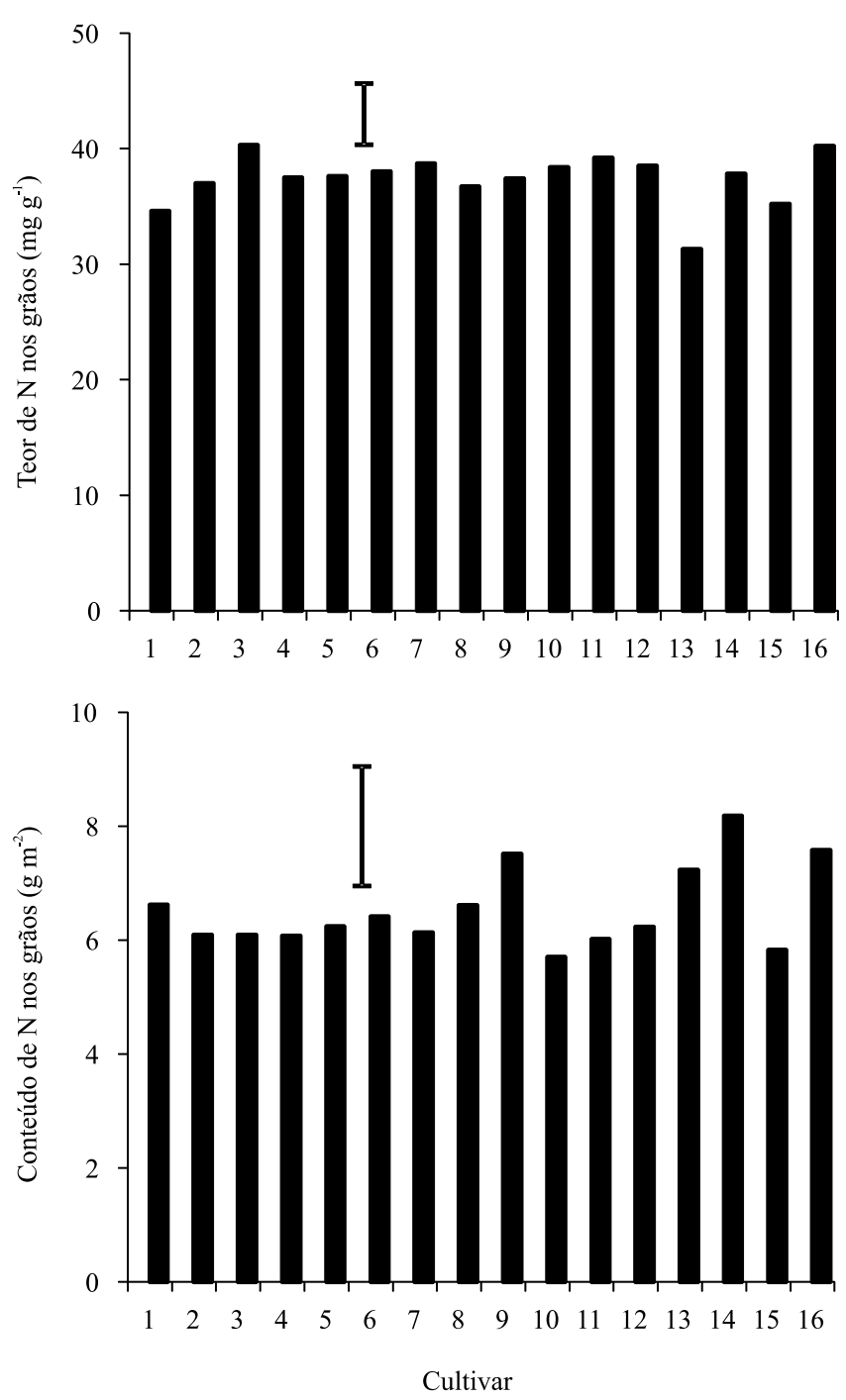

Figura 2. Teor e conteúdo de nitrogênio em grãos de 16 cultivares de feijoeiro-comum, em sistema orgânico de produção, em Seropédica, RJ, em 2011. Barras verticais representam a diferença mínima significativa entre cultivares, pelo teste de Duncan a $5 \%$ de probabilidade. Cultivares: 1, BRS Radiante; 2, Bolinha; 3, Jalo Precoce; 4, Kaboon; 5, Manteigão; 6, Constanza; 7, Ouro Negro; 8, BRS Marfim; 9, BRS Campeiro; 10, BRS Valente; 11, BRS Supremo; 12, BRS Pitanga; 13, Aporé; 14, BRS Pontal; 15, BRS Estilo; 16, BRS Vereda. 


\section{Conclusões}

1. As cultivares de feijoeiro-comum (Phaseolus vulgaris) BRS Pontal, BRS Campeiro, BRS Radiante, Aporé e Constanza apresentam elevada produtividade de grãos em sistema orgânico de produção.

2. As cultivares de feijoeiro-comum com grãos de tipos especiais apresentam bom desempenho em cultivo orgânico, com produtividade similar às cultivares com grãos dos tipos preto e carioca.

\section{Agradecimentos}

À Embrapa Arroze Feijão e ao pesquisador Leonardo Cunha Melo, pelo fornecimento das sementes das cultivares BRS avaliadas nos experimentos.

\section{Referências}

ARAÚJO, A.P.; TEIXEIRA, M.G. Nitrogen and phosphorus harvest indices of common bean cultivars: implications for yield quantity and quality. Plant and Soil, v.257, p.425-433, 2003. DOI: 10.1023/A:1027353822088.

ARAÚJO,A.P.; TEIXEIRA, M.G. Relationships between grain yield and accumulation of biomass, nitrogen and phosphorus in common bean cultivars. Revista Brasileira de Ciência do Solo, v.32, p.1977-1986, 2008. DOI: 10.1590/S0100-06832008000500019.

ARAÚJO, A.P.; TEIXEIRA, M.G. Variabilidade dos índices de colheita de nutrientes em genótipos de feijoeiro e sua relação com a produção de grãos. Revista Brasileira de Ciência do Solo, v.36, p.137-146, 2012. DOI: 10.1590/s0100-06832012000100015.

ARAÚJO, A.P.; TEIXEIRA, M.G.; ALMEIDA, D.L. de. Growth and yield of common bean cultivars at two soil phosphorus levels under biological nitrogen fixation. Pesquisa Agropecuária Brasileira, v.35, p.809-817, 2000. DOI: 10.1590/ S0100-204X2000000400019.

AZADI, H.; SCHOONBEEK, S.; MAHMOUDI, H.; DERUDDER, B.; DE MAEYER, P.; WITLOX, F. Organic agriculture and sustainable food production system: main potentials. Agriculture, Ecosystems and Environment, v.144, p.92-94, 2011. DOI: 10.1016/j.agee.2011.08.001.

BROUGHTON, W.J.; HERNÁNDEZ, G.; BLAIR, M.; BEEBE, S.; GEPTS, P.; VANDERLEYDEN, J. Beans (Phaseolus spp.) model food legumes. Plant and Soil, v.252, p.55-128, 2003. DOI: 10.1023/A:1024146710611.

CARVALHO, W.P. de; WANDERLEY, A.L. Avaliação de cultivares de feijão (Phaseolus vulgaris) para o plantio em sistema orgânico no Distrito Federal. Ciência e Agrotecnologia, v.31, p.605-611, 2007.

COMPANHIA NACIONAL DE ABASTECIMENTO. Séries históricas. Disponível em: <http://www.conab.gov.br/conteudos. php?a=1252\&>. Acesso em: 15 fev. 2015.
GRAHAM, P.H.; ROSAS, J.C.; DE JENSEN, C.E.; PERALTA, E.; TLUSTY, B.; ACOSTA-GALLEGOS, J.; PEREIRA, P.A.A. Addressing edaphic constraints to bean production: the Bean/ Cowpea CRSP project in perspective. Field Crops Research, v.82, p.179-192, 2003. DOI: 10.1016/S0378-4290(03)00037-6.

HARDARSON, G.; BLISS, F.A.; CIGALES-RIVERO, M.R.; HENSON, R.A.; KIPE-NOLT, J.A.; LONGERI, L.; MANRIQUE, A.; PEÑA-CABRIALES, J.J.; PEREIRA, P.A.A.; SANABRIA, C.A.; TSAI, S.M. Genotypic variation in biological nitrogen fixation by common bean. Plant and Soil, v.152, p.59-70, 1993. DOI: $10.1007 / \mathrm{BF} 00016333$.

IBGE. Censo agropecuário 2006: agricultura familiar: primeiros resultados. Rio de Janeiro, 2009. Não paginado.

MAEDER, P.; FLIESSBACH, A.; DUBOIS, D.; GUNST, L.; FRIED, P.; NIGGLI, U. Soil fertility and biodiversity in organic farming. Science, v.296, p.1694-1697, 2002. DOI: 10.1126/ science. 1071148 .

MOREIRA, J.A.A.; SILVEIRA, P.M. da; STONE, L.F. Irrigação. In: ARAUJO, R.S.; RAVA, C.A.; STONE, L.F.; ZIMMERMANN, M.J. de O. (Coord.). Cultura do feijoeiro comum no Brasil. Piracicaba: Potafos, 1996. p.465-521.

MURPHY, K.M.; CAMPBELL, K.G.; LYON, S.R.; JONES, S.S. Evidence of varietal adaptation to organic farming systems. Field Crops Research, v.102, p.172-177, 2007. DOI: 10.1016/j. fcr.2007.03.011.

PIHA, M.I.; MUNNS, D.N. Nitrogen fixation potential of beans (Phaseolus vulgaris L.) compared with other grain legumes under controlled conditions. Plant and Soil, v.98, p.169-182, 1987. DOI: 10.1007/BF02374821.

PONTI, T. de; RIJK, B.; VAN ITTERSUM, M.K. The crop yield gap between organic and conventional agriculture. Agricultural Systems, v.108, p.1-9, 2012. DOI: 10.1016/j.agsy.2011.12.004.

POST, E.; SCHAHCZENSKI, J. Understanding organic pricing and costs of production. Butte: National Sustainable Agriculture Information Service, 2012. 11p. Disponível em: <http://web. extension.illinois.edu/smallfarm/downloads/51366.pdf $>$. Acesso em: 10 dez. 2014.

RAMALHO, M.A.P.; SANTOS, J.B. dos; ZIMMERMANN, M.J. de $O$. Genética quantitativa em plantas autógamas: aplicações ao melhoramento do feijoeiro. Goiânia: Ed. da UFG, 1993. 271p.

RIBEIRO, N.D.; DOMINGUES, L. da S.; GRUHN, E.M.; ZEMOLIN, A.E.M.; RODRIGUES, J. de A. Desempenho agronômico e qualidade de cozimento de linhagens de feijão de grãos especiais. Revista Ciência Agronômica, v.45, p.92-100, 2014. DOI: $10.1590 / \mathrm{S} 1806-66902014000100012$.

SACCO, D.; MORETTI, B.; MONACO, S.; GRIGNANI, C. Six-year transition from conventional to organic farming: effects on crop production and soil quality. European Journal of Agronomy, v.69, p.10-20, 2015. DOI: 10.1016/j.eja.2015.05.002.

SANTOS, H.G. dos; JACOMINE, P.K.T.; ANJOS, L.H.C. dos; OLIVEIRA, V.A. de; OLIVEIRA, J.B. de; COELHO, M.R.; LUMBRERAS, J.F.; CUNHA, T.J.F. (Ed.). Sistema brasileiro de classificação de solos. 2.ed. Rio de Janeiro: Embrapa Solos, 2006. $306 \mathrm{p}$.

Pesq. agropec. bras., Brasília, v.50, n.9, p.797-806, set. 2015 DOI: 10.1590/S0100-204X2015000900008 
SILVA, F.C. da. (Ed.). Manual de análises químicas de solos, plantas e fertilizantes. 2.ed. Brasília: Embrapa Informação Tecnológica; Rio de Janeiro: Embrapa Solos, 2009. 627p.

SINGH, S.P.; GEPTS, P.; DEBOUCK, D.G. Races of common bean (Phaseolus vulgaris L., Fabaceae). Economic Botany, v.45, p.379-396, 1991. DOI: 10.1007/BF02887079.

SINGH, S.P.; TERÁN, H.; MUÑOZ-PEREA, C.G.; LEMA, M.; DENNIS, M.; HAYES, R.; PARROTT, R.; MULBERRY, K.; FULLMER, D.; SMITH, J. Dry bean landrace and cultivar performance in stressed and nonstressed organic and conventional production systems. Crop Science, v.49, p.1859-1866, 2009. DOI: 10.2135/cropsci2008.10.0578.

THUNG, M.; SOARES, D.M.; AIDAR, H. Agregação de valores com feijões especiais. In: KLUTHCOUSKI, J.; STONE, L.F.; AIDAR, H. (Ed.). Fundamentos para uma agricultura sustentável, com ênfase na cultura do feijoeiro. Santo Antônio de Goiás: Embrapa Arroz e Feijão, 2009. p.81-96.

WESTERMANN, D.T.; TERÁN, H.; MUÑOZ-PEREA, C.G.; SINGH, S.P. Plant and seed nutrient uptake in common bean in seven organic and conventional production systems. Canadian Journal of Plant Science, v.91, p.1089-1099, 2011. DOI: 10.4141/cjps10114.

Recebido em 21 de março de 2014 e aprovado em 20 de julho de 2015 